\title{
The Kinetic Properties and Reaction Mechanism of Histamine Methyltransferase from Human Skin
}

\author{
David M. FRANCIS, ${ }^{*}$ Michael F. THOMPSON and Malcolm W. GREAVES \\ Department of Pharmacology, Institute of Dermatology, Homerton Grove, London E9 6BX, U.K.
}

(Received 8 October 1979)

\begin{abstract}
1. The substrate kinetic properties of histamine methyltransferase from human skin were studied at limiting concentrations of both histamine and $S$-adenosylmethionine. Substrate inhibition by histamine was observed at concentrations above $10 \mu \mathrm{M}$. Primary plots showed evidence of a sequential reaction mechanism. The Michaelis constants were derived from secondary plots of slopes from the primary plots ([S]/v versus $[\mathrm{S}]$ ) versus reciprocal of the second substrate concentration. The mean $K_{\mathrm{m}}$ values for histamine and $S$-adenosylmethionine were 4.2 and $1.8 \mu \mathrm{M}$ respectively. 2 . Histamine in concentrations of $25-100 \mu \mathrm{M}$ inhibited enzyme activity uncompetitively with respect to $S$-adenosylmethionine. No substrate inhibition was observed with $S$-adenosylmethionine. 3. To elucidate the reaction mechanism further, inhibition by the two products, $S$-adenosylhomocysteine and 1-methylhistamine, was studied. $S$-Adenosylhomocysteine inhibited non-competitively with respect to histamine and competitively with respect to $S$-adenosylmethionine. 1-Methylhistamine inhibited non-competitively with respect to histamine and to $S$-adenosylmethionine. These results are interpreted as providing evidence for an ordered sequential $\mathrm{Bi} \mathrm{Bi}$ reaction mechanism, with the methyl-group donor $S$-adenosylmethionine as the first substrate that adds to the enzyme and histamine as the second substrate. 1-Methylhistamine is the first product to leave the enzyme and $S$-adenosylhomocysteine is the second. 4. The results are discussed in terms of the possible role that this enzyme could play in the modulation of histamine-mediated reactions in skin.
\end{abstract}

$N$-Methylation of the imidazole ring of histamine to form 1-methylhistamine is one of the two major pathways for the inactivation of histamine in mammals (Schayer, 1959). This reaction is catalysed by the enzyme histamine methyltransferase (EC 2.1.1.8) described by Brown et al. (1959) and utilizes $S$-adenosylmethionine as a methyl-group donor. Since histamine is a mediator of a variety of common dermatoses in man, the presence of histamine methyltransferase in human skin (Francis et al., 1977) could be important in modulating the severity of such histamine-induced reactions. Preliminary work on guinea pigs indicated that inhibition of histamine degradation in vivo could significantly enhance the severity of the histaminemediated homologous $72 \mathrm{~h}$ passive cutaneous anaphylaxis reaction in this species (Yamamoto et al., 1976). In order to evaluate the role of histamine methyltransferase in human skin it is important to understand the kinetic properties of the enzyme and its reaction mechanism.

* To whom all correspondence should be addressed.
There is conflicting evidence in the literature about the reaction mechanism of histamine methyltransferase derived from animal tissues. Barth et al. (1975) proposed an ordered sequential $\mathrm{Bi} \mathrm{Bi}$ mechanism on the basis of substrate kinetic and product-inhibition studies for histamine methyltransferase derived from pig gastric mucosa. Thithapandha \& Cohn (1978) produced evidence of a Ping Pong mechanism for purified histamine methyltransferase from guinea-pig brain. It would seem very unlikely that mammalian histamine methyltransferase, albeit from two different species and tissues, should have such radically different reaction mechanisms. Therefore we used the systematic approach described by Cleland (1963a,b,c, 1970) to determine the reaction mechanism and kinetic properties of the enzyme from human skin.

The initial-velocity patterns for the enzyme reaction at subsaturating concentrations of both substrates, histamine and $S$-adenosylmethionine, in the presence and absence of the products, 1methylhistamine and $S$-adenosylhomocysteine, were 
analysed. Initial-velocity patterns from substrate kinetic studies can distinguish between Ping Pong and sequential mechanisms; product-inhibition studies can further elucidate the type of reaction mechanism and the sequence of addition of substrates to the enzyme. Substrate inhibition by histamine was also studied for further confirmation of the mechanism. The results indicate that histamine methyltransferase from human skin has an ordered sequential $\mathrm{Bi} \mathrm{Bi}$ reaction mechanism.

\section{Materials and Methods}

\section{Reagents}

$$
S \text {-Adenosyl-L- }\left[\mathrm{Me}^{-14} \mathrm{C}\right] \text { methionine } \quad(59-62 \mathrm{mCi} /
$$
$\mathrm{mmol})$ and $\mathrm{n}-\left[{ }^{14} \mathrm{C}\right]$ hexadecane $(0.526 \mu \mathrm{Ci} / \mathrm{g})$ reference standard for liquid-scintillation counting of radioactivity were obtained from The Radiochemical Centre (Amersham, Bucks., U.K.). $S$ Adenosyl-L-homocysteine and $S$-adenosyl-L-methionine iodide (grade 1) were obtained from Sigma (London) Chemical Co. (Poole, Dorset, U.K.). 1-Methylhistamine [1-methyl-4-( $\beta$-aminoethyl)imidazole] dihydrochloride (grade A) was supplied by Calbiochem (Bishop's Stortford, Herts., U.K.). Histamine dihydrochloride (puriss) was supplied by Koch-Light Laboratories (Colnbrook, Bucks., U.K.). Isopentanol (3-methyl-1-butanol) was obtained from Aldrich Chemical Co. (Gillingham, Dorset, U.K.). Liquid-scintillation chemicals included 2ethoxyethanol, sulphur-free toluene, naphthalene (from BDH Chemicals, Poole, Dorset, U.K.) and 2,5-diphenyloxazole (from Intertechnique, Uxbridge, Middlesex, U.K.). All other chemicals used were obtained from BDH Chemicals and were of AnalaR grade or the highest purity available. Water was distilled and de-ionized before use.

\section{Preparation and storage of substrates}

A $2 \mathrm{~mm}$ stock solution of histamine dihydrochloride was prepared in $50 \mathrm{~mm}$-sodium phosphate buffer $\left(9.5 \mathrm{mM}-\mathrm{NaH}_{2} \mathrm{PO}_{4} / 40.5 \mathrm{mM}-\mathrm{NH}_{2} \mathrm{HPO}_{4}\right)$, $\mathrm{pH} 7.43$, and stored in small portions at $-20^{\circ} \mathrm{C}$. The specific radioactivity of the $S$-adenosyl $\left[\mathrm{Me}^{\left.-{ }^{14} \mathrm{C}\right]}\right.$ methionine used in all the experiments described was $4 \mathrm{mCi} / \mathrm{mmol}$. A stock solution of $2.5 \mathrm{mM}$ at this specific radioactivity was prepared by mixing a solution of $S$-adenosyl[ $\left.\mathrm{Me}^{-14} \mathrm{C}\right]$ methionine at a specific radioactivity of $59-62 \mathrm{mCi} / \mathrm{mmol}$ with a solution of $S$-adenosylmethionine iodide in $50 \mathrm{~mm}$ sodium phosphate buffer (6.15 mM- $\mathrm{Na}_{2} \mathrm{HPO}_{4} /$ $\left.43.85 \mathrm{~mm}-\mathrm{NaH}_{2} \mathrm{PO}_{4}\right), \mathrm{pH} 6.0$, at the required concentration and stored in small portions at $-20^{\circ} \mathrm{C}$.

\section{Measurement of histamine content of human skin}

To determine the histamine content of each sample of skin, a small piece of whole skin was boiled in $5 \mathrm{ml}$ of $0.4 \mathrm{M}-\mathrm{HClO}_{4}$ for $5 \mathrm{~min}$. The supernatant was centrifuged at $2000 \mathrm{~g}$ for $15 \mathrm{~min}$ in an MSE Mistral $6 \mathrm{~L}$ centrifuge at $20^{\circ} \mathrm{C}$, and the histamine concentration was determined fluorimetrically by the method of Shore et al. (1959) with a Technicon Auto-Analyzer II system for histamine, with a lower limit of detection of $1 \mathrm{ng}$ of histamine base $/ \mathrm{ml}$. Samples were diluted with $0.4 \mathrm{M}-\mathrm{HClO}_{4}$ to give readings in the range of the histamine standards used (1-30 ng of histamine base $/ \mathrm{ml}$ ).

\section{Preparation of human skin histamine methyl- transferase}

Clinically normal human skin was obtained from two females undergoing abdominal skin-reduction operations. The skin was kept on ice until the subcutaneous fat could be removed. The intact skin was then stored at $-20^{\circ} \mathrm{C}$ in an air-tight container for a period of not more than 3 weeks. The two skin samples were used to prepare two separate preparations of histamine methyltransferase for use in the subsequent experiments described. Preparation 1 was derived from $68 \mathrm{~g}$ of skin from a Caucasian female aged 27 years and preparation 2 from $49 \mathrm{~g}$ of skin from a Caucasian female aged 46 years.

We have previously shown that almost all the histamine methyltransferase activity of human skin is located in the epidermis and upper dermis (Francis et al., 1977). Because of the difficulties of homogenizing large amounts of whole skin, the enzyme activity was extracted by stretching the skin and vigorously scraping off the epidermis and upper dermis with a blunt scalpel blade. The scrapings were homogenized in $50 \mathrm{~mm}$-sodium phosphate buffer, $\mathrm{pH} 7.43$. A ratio of $1 \mathrm{~g}$ of scrapings to $6 \mathrm{ml}$ of buffer was used. The homogenizer (type X 1020; Internationale Laboratoriums-Apparate G.m.b.H., Ballrichten/Dottingen, West Germany) was fitted with a $1 \mathrm{~cm}$-diam. shaft. Samples of the scrapings in buffer were homogenized for three $10 \mathrm{~s}$ periods at speed setting 7, with the homogenization tube kept cold in an ice bath. The homogenates were pooled and centrifuged at $1600 \mathrm{~g}$ for $15 \mathrm{~min}$ at $4^{\circ} \mathrm{C}$ in an MSE Mistral $6 \mathrm{~L}$ centrifuge $\left(r_{\mathrm{av}} .23 \mathrm{~cm}\right)$. The supernatant was removed and subjected to the following procedures, according to the preparation. The supernatant from preparation 1 was dialysed for $20 \mathrm{~h}$ at $4^{\circ} \mathrm{C}$ against seven 1 -litre changes of $1 \mathrm{~mm}$-sodium phosphate buffer, $\mathrm{pH} 7.43$, to remove any endogenous substrates. The dialysis residue was freezedried and used as the source of histamine methyltransferase in all subsequent experiments except where otherwise indicated. The freeze-dried enzyme was stable for 6 months at $4^{\circ} \mathrm{C}$. The supernatant from preparation 2 was dialysed for $20 \mathrm{~h}$ at $4^{\circ} \mathrm{C}$ against five 1-litre changes of $50 \mathrm{~mm}$-sodium phosphate buffer, $\mathrm{pH}$ 7.43. The dialysis residue was frozen in small portions and stored at $-20^{\circ} \mathrm{C}$ as a source of the enzyme. This method of storage resulted in a 
gradual loss of enzyme activity of approx. 50\% in 6 months.

The recovered enzyme activity was determined for the dialysed $104000 \mathrm{~g}$ supernatant derived from each skin sample and expressed in terms of the wet weight of whole skin. Enzyme activity was measured at $50 \mu \mathrm{M}$-S -adenosylmethionine and $10 \mu \mathrm{M}$-histamine as described under 'Histamine methyltransferase assay' below.

\section{Histamine methyltransferase assay}

Histamine methyltransferase activity was assayed by measuring the formation of $1-\left[M e^{-14} \mathrm{C}\right]$ methylhistamine by a modification of the method of Snyder \& Axelrod (1965). Incubations were carried out in duplicate in silicone-treated $15 \mathrm{ml}$ Pyrex test tubes under air, stoppered with siliconerubber bungs. The total incubation volume was $500 \mu l$ containing histamine, $S$-adenosyl $\left[\mathrm{Me}^{\left.-{ }^{14} \mathrm{C}\right]-}\right.$ methionine and a source of histamine methyltransferase at the required concentration, plus inhibitor where relevant, in $50 \mathrm{~mm}$-sodium phosphate buffer, pH 7.43. Samples of freeze-dried enzyme preparation 1 were dissolved in $50 \mathrm{~mm}$ sodium phosphate buffer, $\mathrm{pH} 7.43$, to give the required enzyme activity for each experiment. Samples of preparation 2, which had been stored frozen in $50 \mathrm{~mm}$-sodium phosphate buffer, were thawed then used directly in the substrae kinetic experiment described. The components of the reaction mixtures were added to the tubes on ice, with the enzyme as the final addition.

The reaction was started by transferring the tubes from ice buckets to racks, which were placed in the water bath simultaneously. All samples and blankrate tubes were incubated for $20 \mathrm{~min}$ at $37^{\circ} \mathrm{C}$ in a Grant shaking water bath. The reaction was stopped by transferring the racks of tubes from the water bath to a Grant cooling water bath at a temperature of $-8^{\circ} \mathrm{C}$ for $2 \mathrm{~min}$ and the tubes were returned to ice buckets. The reaction mixtures were adjusted to $\mathrm{pH} 10.4$ by the addition of $300 \mu \mathrm{l}$ of $0.5 \mathrm{M}$-borate buffer $(0.5 \mathrm{M}$-boric acid/ $0.5 \mathrm{M}-\mathrm{NaOH})$. Then $6 \mathrm{ml}$ of isopentanol/toluene $(2: 3, \mathrm{v} / \mathrm{v})$ was added to each tube in a random order and the tubes were vigorously vortexed for $30 \mathrm{~s}$. The stoppered tubes were centrifuged at $1000 \mathrm{~g}$ for $15 \mathrm{~min}$ at $20^{\circ} \mathrm{C}$ to separate the phases. A $4 \mathrm{ml}$ portion of the organic phase was removed from each tube, added to a vial containing $8 \mathrm{ml}$ of scintillation fluid and its radioactivity counted as described under 'Scintillation counting of radioactivity' below. The extraction procedure described above had an efficiency of 53\% which was constant over a range of concentrations of ${ }^{14} \mathrm{C}$-labelled 1-methylhistamine from 15.9 to $863.0 \mathrm{nM}$; this range of 1 -methylhistamine concentrations was greater than the range of concentra- tions formed in any of the experiments described in this paper. The extraction efficiency was determined using ${ }^{14} \mathrm{C}$-labelled 1 -methylhistamine which had been enzymically synthesized from ${ }^{14} \mathrm{C}$-labelled histamine and purified by t.l.c. using a solvent system which has been described previously (Francis et al., 1977).

Blank-rate tubes were set up for each $S$-adenosylmethionine concentration, these being identical with the sample tubes except that histamine was omitted from the reaction mixture. The blank 'rate' was caused by the extraction of trace amounts of $S$ adenosyl $\left[\mathrm{Me}^{-{ }^{14}} \mathrm{C}\right]$ methionine from the incubation mixture and was related to the concentration of $S$-adenosyl $\left[\mathrm{Me}^{-14} \mathrm{C}\right]$ methionine. Blank rates at each $S$-adenosylmethionine concentration were subtracted from the overall rates observed at the respective $S$-adenosylmethionine concentrations. The blank rates for both enzyme preparations were the same as blank rates obtained when the enzyme solution was replaced by a corresponding volume of $50 \mathrm{~mm}$-sodium phosphate buffer. The enzyme preparations therefore contained no interfering endogenous histamine after dialysis.

Initial velocities for the kinetic plots were calculated as d.p.m. of $1-\left[\mathrm{Me}^{-14} \mathrm{C}\right]$ methylhistamine formed/min, without correction for the overall extraction efficiency, as this was a constant factor for all the tubes in any experiment. Every experiment described was performed in two parts because of the number of sample tubes involved. Both parts of the experiment were performed on the same day, the same reagent and enzyme solutions being used. The sample tubes were randomized between the two parts of the experiment as far as possible with respect to the substrate concentrations.

At substrate concentrations of $50 \mu \mathrm{M}-S$-adenosylmethionine and $10 \mu \mathrm{M}$-histamine, preparations 1 and 2 had enzyme activities of 5.0 and $5.6 \mathrm{nmol}$ of histamine methylated/h per $\mathrm{mg}$ of protein respectively; $1 \mathrm{nmol}$ of $1-\left[\mathrm{Me}^{14} \mathrm{C}\right]$ methylhistamine formed with the use of $S$-adenosyl $\left[\mathrm{Me}^{-14} \mathrm{C}\right]$ methionine at a specific radioactivity of $4 \mathrm{mCi} / \mathrm{mmol}$ is equivalent to 8880 d.p.m. Because of the losses in extraction this would correspond to a value of $3138 \mathrm{~d}$.p.m. as measured in the assay. The protein content of the reaction mixtures in the experiments with enzyme preparation 1 was in the range $122-168 \mu \mathrm{g}$, and in the substrate kinetic experiment with preparation 2 it was $77 \mu \mathrm{g}$.

Both enzyme preparations were examined for any histamine-degrading enzyme activity other than histamine methyltransferase operating under the conditions of the assay and competing for histamine. Duplicate samples containing the enzyme preparations at the concentrations used in the histamine methyltransferase assay were incubated for $60 \mathrm{~min}$ at $37^{\circ} \mathrm{C}$ with $2 \mu \mathrm{M}$ - and $10 \mu \mathrm{M}$-histamine in $500 \mu \mathrm{l}$ of 
50 mm-sodium phosphate buffer, $\mathrm{pH} 7.43$. At the end of the incubation, $4.5 \mathrm{ml}$ of $\mathrm{HClO}_{4}$ solution was added to give a final concentration of $0.4 \mathrm{M}$, and the contents of the tubes were vortex-mixed immediately and centrifuged at $2000 \mathrm{~g}$ for $15 \mathrm{~min}$ to give a protein-free supernatant. Identical control samples were set up and acidified immediately, and prepared for histamine assay as described for the incubated samples. The histamine content of the samples was measured fluorimetrically as described above.

\section{Scintillation counting of radioactivity}

Liquid-scintillation fluid was prepared in the proportions $1500 \mathrm{ml}$ of toluene, $900 \mathrm{ml}$ of 2-ethoxyethanol, $112.5 \mathrm{~g}$ of naphthalene and $10.5 \mathrm{~g}$ of 2,5-diphenyloxazole, the final mixture containing $2 \%$ (v/v) methanol. An LKB Ultrobeta 1210 scintillation counter was used, d.p.m. being calculated by the external-standard channels-ratio method. Counting efficiency for ${ }^{14} \mathrm{C}$ was determined and a quench curve was prepared by using standardized $n-\left[{ }^{14} \mathrm{C}\right]-$ hexadecane as an internal standard in vials containing $4 \mathrm{ml}$ portions of isopentanol/toluene $(2: 3$, $\mathrm{v} / \mathrm{v})$ and $8 \mathrm{ml}$ of scintillation fluid. ${ }^{14} \mathrm{C}$ radioactivity was counted with an efficiency of $89 \%$.

Radioactivities of vials were counted for a total of $10^{4}$ counts. Sample vials from incubation mixtures where there had been formation of $1-\left[\mathrm{Me}^{-14} \mathrm{C}\right]-$ methylhistamine gave $2 \sigma$ standard-error values between 2.0 and $3.0 \%$, depending on the concentration of $S$-adenosylmethionine. Vials derived from incubation mixtures to measure the blank rates gave higher $2 \sigma$ standard-error values, reaching $5.7 \%$ at the lowest $S$-adenosylmethionine concentration used $(4 \mu \mathrm{M})$. The external-standard radioactivity was counted for $1 \mathrm{~min}$.

\section{Kinetic studies}

The reaction rates were linear for at least $20 \mathrm{~min}$ at $37^{\circ} \mathrm{C}$, at the highest and lowest substrate concentrations used. Kinetic results were plotted as $[\mathrm{S}] / v$-versus-[S] plots except where otherwise stated. The primary plots presented show data points as the means of duplicate values. Results were analysed by linear regression by using the method of least squares. $K_{\mathrm{m}}$ values were derived from secondary plots of slopes from the primary plots versus the reciprocal of the second substrate concentration by the procedure of Florini \& Vestling (1957). $K_{\mathrm{s}}$ values were derived by first obtaining, from the [ $S$-adenosylmethionine] $/ v$-versus-[ $S$-adenosylmethionine] primary plot, secondary plots of slopes and intercepts versus the reciprocal of the second substrate (histamine) concentration; evaluation of the ratio of the slope from the intercepts replot to the slope of the slopes replot yielded the $K_{\mathrm{s}}$ for $S$-adenosylmethionine. $K_{\mathrm{s}}$ values for histamine are not appropriate to the proposed mechanism for this enzyme. Product-inhibition constants were derived from secondary plots of slopes and intercepts versus relevant inhibitor concentration (Cleland, 1963b, 1970). All secondary plots were linear. Because the slopes and intercepts are derived from $[\mathrm{S}] / v$-versus[S] primary plots, our $K_{\text {is }}$ values are equivalent to Cleland's $K_{\text {if }}$ values derived from double-reciprocal plots, and vice versa.

\section{Determination of protein}

This was performed by the method of Lowry et al. (1951), with human plasma albumin as standard. This was obtained as an aqueous $10 \%(\mathrm{w} / \mathrm{v})$ solution from the Blood Products Laboratory, Lister Institute, Elstree, Herts., U.K.

\section{Results}

Histamine content and histamine methyltransferase activity of human skin

The histamine content of the two skin samples from which enzyme preparations 1 and 2 were derived was $17.2 \mathrm{nmol} / \mathrm{g}$ wet wt. of whole skin and $30.2 \mathrm{nmol} / \mathrm{g}$ wet wt. respectively. The histamine methyltransferase activities for skin samples 1 and 2 were $30.9 \mathrm{nmol}$ of histamine methylated/h per $\mathrm{g}$ wet wt. of whole skin and $19.2 \mathrm{nmol} / \mathrm{h}$ per $\mathrm{g}$ wet. wt. respectively. There was negligible loss of histamine in the samples incubated for $60 \mathrm{~min}$ in the absence of $S$-adenosylmethionine, being less than $2 \%$ of the total for both preparations at both histamine concentrations used. Therefore these unpurified preparations do not contain significant amounts of diamine oxidase, the other major histamine-degrading enzyme, in confirmation of the findings reported by Francis et al. (1977).

\section{Kinetic studies}

Substrate kinetics. Figs. $1(a)$ and $1(b)$ show typical results of plots of $[\mathbf{S}] / v$ versus $[\mathbf{S}]$ made with respect to histamine and $S$-adenosylmethionine respectively; the corresponding slopes of secondary plots are Figs. $1(c)$ and $1(d)$ respectively. The lines of the plots of Figs. $1(a)$ and $1(b)$ converged to the left of the ordinate, with intersection below the abscissa. The intersection of the lines to the left of the ordinate rules out the possibility of a Ping Pong mechanism and is consistent with a sequential mechanism. Table 1 shows the kinetic constants obtained for the two preparations of histamine methyltransferase from human skin. The values obtained were similar for both preparations. The mean $K_{\mathrm{m}}$ values for $S$-adenosylmethionine and histamine were 1.82 and $4.20 \mu \mathrm{M}$ respectively. The mean dissociation constant, $K_{\mathrm{s}}$, for $S$-adenosylmethionine was $7.48 \mu \mathrm{M}$.

Product inhibition. Figs. 2 and 3 are typical plots 

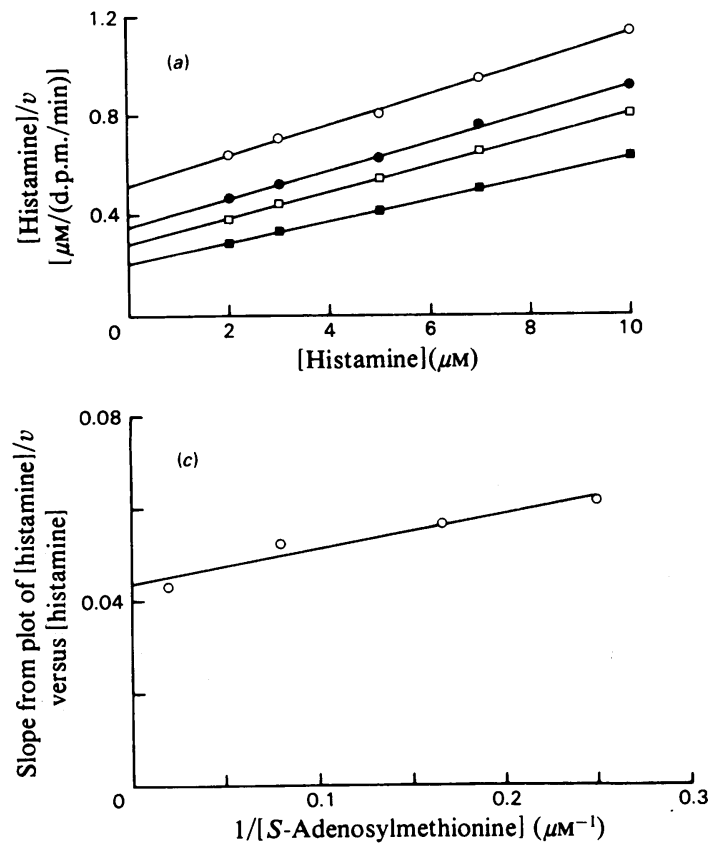
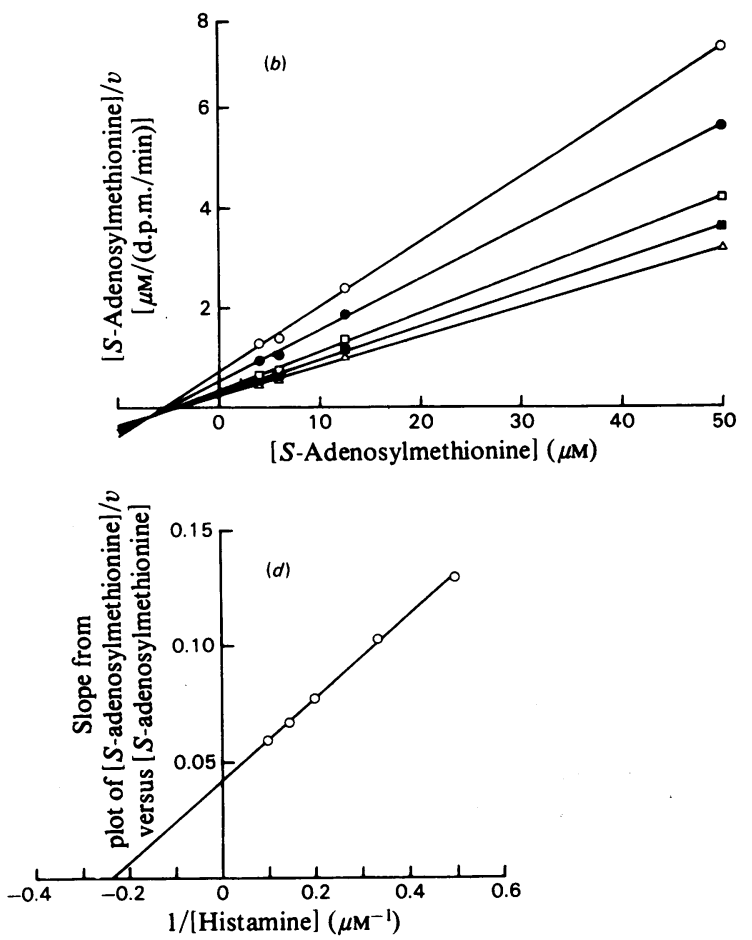

Fig. 1. Substrate kinetic analysis of human skin histamine methyltransferase

(a) Plot of [histamine] $/ v$ versus [histamine] with various $S$-adenosylmethionine concentrations: $\bigcirc, 4 \mu \mathrm{M} ; \boldsymbol{\bullet}, 6 \mu \mathrm{M}$; $\square$, $12.5 \mu \mathrm{M}$; $50 \mu \mathrm{M}$. (b) Plot of $[S$-adenosylmethionine $] / v$ versus $[S$-adenosylmethionine $]$ with various histamine concentrations: $\bigcirc, 2 \mu \mathrm{M} ; \bullet, 3 \mu \mathrm{M} ; \square, 5 \mu \mathrm{M} ; \square, 7 \mu \mathrm{M} ; \Delta, 10 \mu \mathrm{M}$. (c) Secondary plot of slopes from (a) versus $1 /[S$-adenosylmethionine]. $(d)$ Secondary plot of slopes from $(b)$ versus $1 /[$ histamine]. Experimental details are described in the Materials and Methods section.

Table 1. Substrate kinetic constants of human skin histamine methyltransferase The determination of the kinetic constants is described in the text. The sources of histamine methyltransferase are described in the Materials and Methods section.

\begin{tabular}{|c|c|c|c|}
\hline & \multicolumn{3}{|c|}{ Kinetic constants $(\mu \mathrm{M})$} \\
\hline & $K_{\mathrm{m}}$ for $S$-adenosylmethionine & $\begin{array}{c}K_{\mathrm{m}} \text { for histamine } \\
\left(K_{\mathrm{m}}^{\mathrm{B}}\right)\end{array}$ & $\begin{array}{l}\text { Dissociation constant for } \\
S \text {-adenosylmethionine } \\
\left(K_{\mathbf{s}}^{\mathbf{A}}\right)\end{array}$ \\
\hline Preparation $1^{*}$ & $\begin{array}{l}2.08 \\
1.66\end{array}$ & $\begin{array}{l}4.77 \\
3.57\end{array}$ & $\begin{array}{l}7.16 \\
8.29\end{array}$ \\
\hline Preparation $2 \dagger$ & 1.71 & 4.27 & 7.00 \\
\hline Mean & 1.82 & 4.20 & 7.48 \\
\hline
\end{tabular}

* The values shown are for two separate determinations.

† The results for the determination of the $K_{\mathrm{m}}$ values for this enzyme preparation are presented graphically in Fig. 1 .

illustrating the inhibition patterns obtained with 1-methylhistamine and $S$-adenosylhomocysteine respectively. 1-Methylhistamine inhibition with respect to histamine as the varied substrate was clearly non-competitive (Fig. 2a), but the pattern of inhibition obtained where $S$-adenosylmethionine concentration was varied was not so easily interpreted, because the lines intersected very slightly to the left of the ordinate (Fig. $2 b$ ); intersection on the ordinate would have indicated uncompetitive 

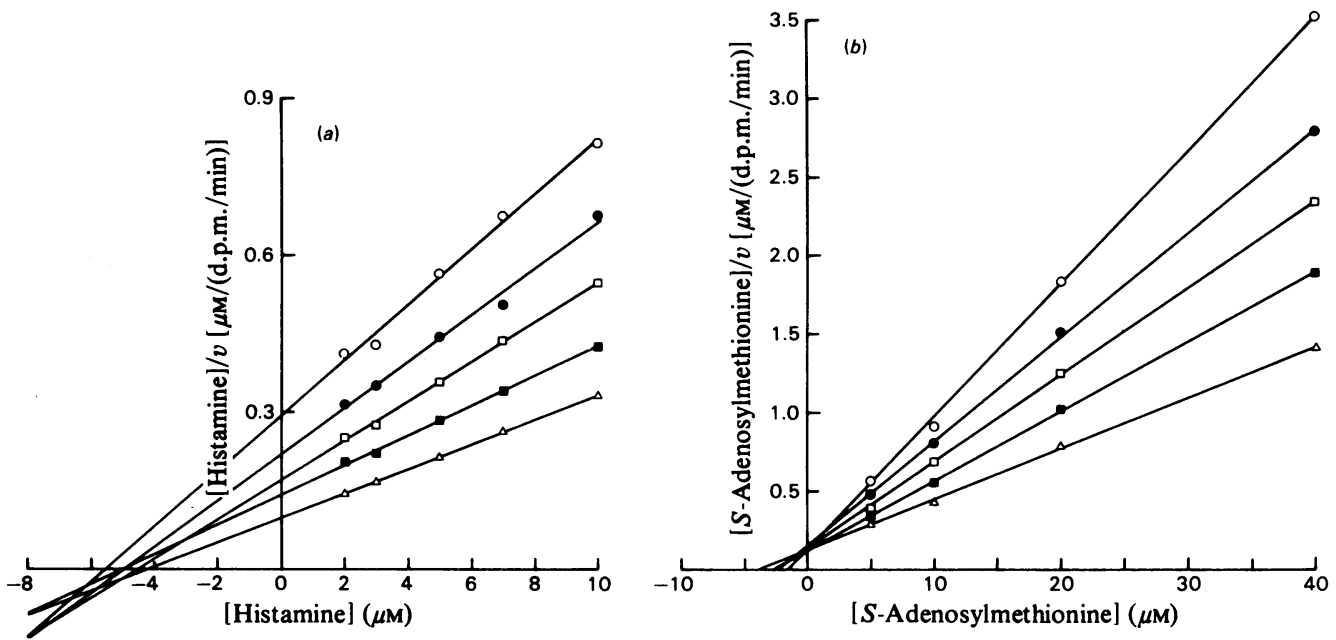

Fig. 2. Inhibition of human skin histamine methyltransferase by 1-methylhistamine

(a) Plot of [histamine] $/ v$ versus [histamine] at constant $50 \mu \mathrm{M}$-S-adenosylmethionine and various 1 -methylhistamine concentrations: $0,50 \mu \mathrm{M} ; 0,35 \mu \mathrm{M} ; \square, 20 \mu \mathrm{M} ; \square, 10 \mu \mathrm{M} ; \Delta$, nil. (b) Plot of [S-adenosylmethionine] $/ v$ versus [S-adenosylmethionine] at constant $10 \mu \mathrm{M}$-histamine and various 1-methylhistamine concentrations: $\mathrm{O}, 50 \mu \mathrm{M}$; $35 \mu \mathrm{M} ;$ ㅁ, $20 \mu \mathrm{M} ; 10 \mu \mathrm{M} ; \Delta$, nil. Experimental details are described in the Materials and Methods section.
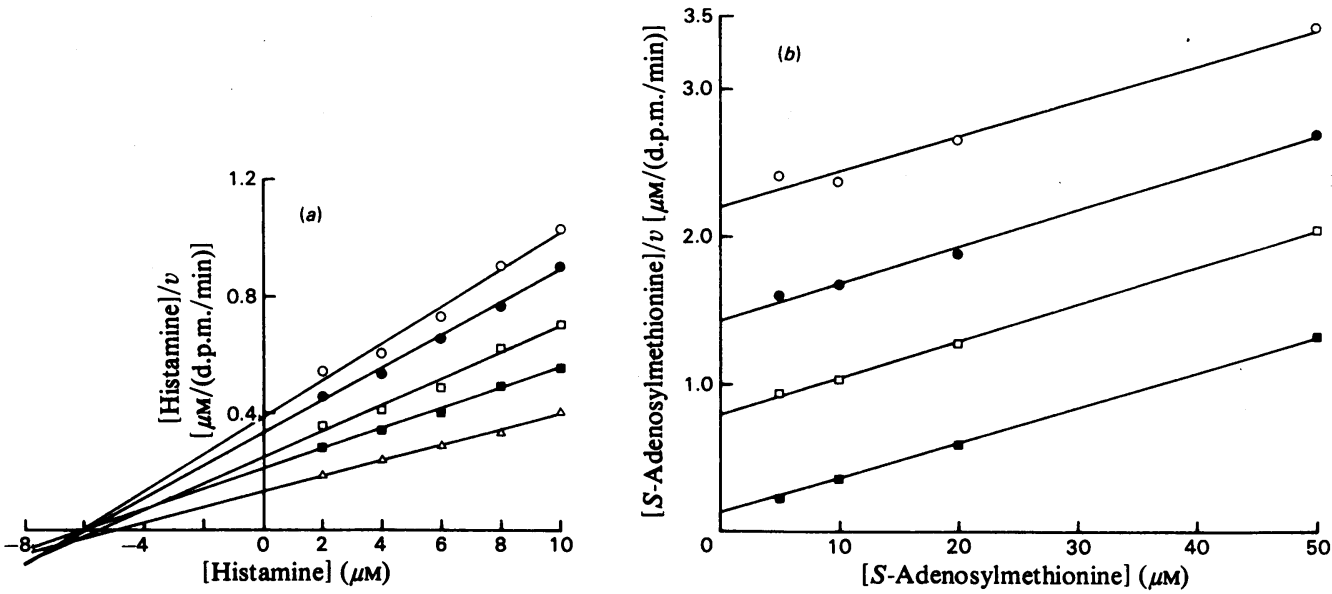

Fig. 3. Inhibition of human skin histamine methyltransferase by $S$-adenosylhomocysteine

(a) Plot of [histamine] $/ v$ versus [histamine] at constant $25 \mu \mathrm{M}-S$-adenosylmethionine and various $S$-adenosylhomocysteine concentrations: $0,20 \mu \mathrm{M} ; 0,15 \mu \mathrm{M} ;$ 매 $10 \mu \mathrm{M} ; 5 \mu \mathrm{M} ; \Delta$, nil. (b) Plot of [S-adenosylmethionine] $/ v$ versus [ $S$-adenosylmethionine] at constant $10 \mu \mathrm{M}$-histamine and various $S$-adenosvlhomocysteine concentrations: $0,30 \mu \mathrm{M} ; 0,20 \mu \mathrm{M} ; \square, 10 \mu \mathrm{M} ; \square$, nil. Experimental details are described in the Materials and Methods section.

inhibition, whereas intersection in the left-hand quadrants is indicative of non-competitive inhibition. Similar results were obtained in three repeat experiments where histamine concentration was held at 10 and $5 \mu \mathrm{M}$. Had the inhibition been truly uncompetitive one would expect that, by virtue of the random error expected in such experiments, an equal number of plots would have shown intersection in the top right-hand quadrant, a phenomenon commonly found in plots of competitive inhibition, objectively assessed, by using the more traditional double-reciprocal graphs; such a finding is of course subjectively not admissible, and one can conclude that the correct intersection point is on the ordinate. 
In none of our studies of the inhibition by 1methylhistamine at varied $S$-adenosylmethionine concentration and constant histamine concentration was there any evidence of focusing of the primary plots to the right of the ordinate. The inhibition was therefore interpreted as non-competitive.

The product-inhibition patterns obtained with S-adenosylhomocysteine are shown in Fig. 3. Fig. $3(a)$ illustrates the non-competitive pattern of inhibition obtained with respect to histamine. The inhibition pattern obtained with respect to $S$-adenosylmethionine (Fig. $3 b$ ) was a series of parallel lines,

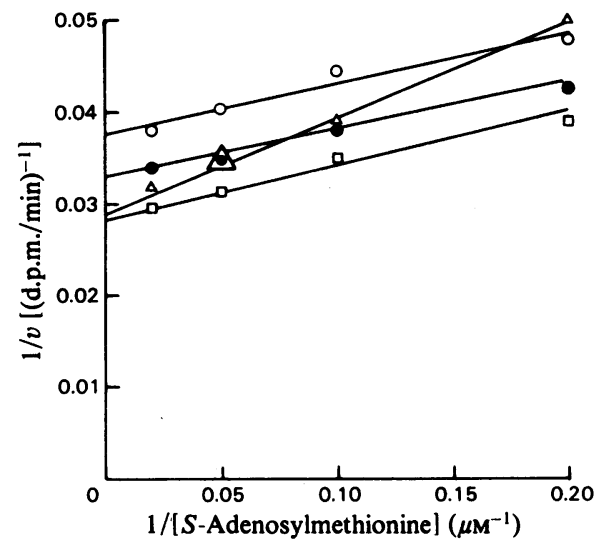

Fig. 4. Substrate inhibition of human skin histamine methyltransferase by histamine

Plot of $1 / v$ versus $1 /[S$-adenosylmethionine $]$ at various histamine concentrations: $0,100 \mu \mathrm{M} ; 0$, $50 \mu \mathrm{M} ; \square, 25 \mu \mathrm{M} ; \Delta, 10 \mu \mathrm{M}$. Experimental details are described in the Materials and Methods section. indicating competitive inhibition. Table 2 gives the $K_{\mathrm{i}}$ values obtained from the secondary plots of slopes and intercepts for all the product inhibitions. The character of the primary plots of the noncompetitive inhibition by 1-methylhistamine with respect to $S$-adenosylmethionine was such that the intercept effect was extremely small with a disproportionately large variance. Consequently the $K_{1 \text { (intercepts) }}$ values representing the competitive component of the inhibition could not be estimated as accurately as was possible for the other cases of non-competitive inhibition. Therefore these values have been included mainly as a guide to their order of magnitude compared with $K_{1(\text { slopes })}$ values. Table 2 shows that the $K_{1(\text { intercepts) }}$ values are of similar magnitude to the $K_{1(\text { slopes })}$ values in the other non-competitive inhibitions, whereas $K_{1 \text { (intercepts) }}$ values are approaching a value that is an order of magnitude greater than $K_{1 \text { (slopes) }}$ values for the non-competitive inhibition by 1 -methylhistamine with respect to $S$-adenosylmethionine. The smaller the $K_{1}$ value, the more potent is the inhibitor effect, and hence it is clear that at $5 \mu \mathrm{M}$-histamine the competitive component of the latter inhibition appears to be increased

Substrate inhibition. The occurrence and type of inhibition produced by a substrate can provide further information about the reaction mechanism. Fig. 4 shows the inhibition pattern produced when the histamine concentration was varied in the range $10-100 \mu \mathrm{M}$ with respect to $S$-adenosylmethionine. The data are plotted in double-reciprocal form for clarity. The lines were obtained by weighted linearregression analysis (Wilkinson, 1961). With increasing histamine concentrations above $10 \mu \mathrm{M}$ the intercepts reach a minimum and then increase. The slopes decrease with increasing histamine con-

Table 2. Inhibition constants for product inhibition of human skin histamine methyltransferase The inhibition constants were calculated from secondary plots of the intercepts and the slopes of the primary plots $([\mathrm{S}] / v$ versus $[\mathrm{S}])$ versus product-inhibitor concentration. The intercept on the ordinate varies with inhibitor concentration if there is a competitive component in the inhibition and the slope varies with inhibitor concentration if there is an uncompetitive component. The number of experiments is indicated in parentheses. Where applicable the values are means.

Inhibition constants derived from $[\mathbf{S}] / v$-versus-[S] primary

Product inhibitor

1-Methylhistamine

1-Methylhistamine

1-Methylhistamine

$S$-Adenosylhomocysteine

$S$-Adenosylhomocysteine
Substrate varied

$S$-Adenosylmethionine

$S$-Adenosylmethione

Histamine

$\boldsymbol{S}$-Adenosylmethionine

Histamine

\begin{tabular}{|c|c|}
\hline $\begin{array}{l}\text { Concn. of fixed } \\
\text { substrate }(\mu \mathrm{M})\end{array}$ & $\begin{array}{l}\text { Nature of } \\
\text { inhibition }\end{array}$ \\
\hline 5 & Non-competitive \\
\hline 10 & Non-competitive \\
\hline 50 & Non-competitive \\
\hline 10 & Competitive \\
\hline 25 & Non-competitive \\
\hline
\end{tabular}
plots $(\mu \mathrm{M})$

$\begin{array}{cc}K_{1 \text { (intercepts) }} & K_{1 \text { (slopes) }} \\ 127(1)^{*} & 30.2(1) \\ 339(3)^{*} & 33(3) \\ 25.6(1) & 39.6(1) \\ 1.1(2) & - \\ 11 \text { (1) } & 13.8(1)\end{array}$

* These values are difficult to estimate accurately because of the nature of the primary plot. See the text for detailed discussion. 
centration before becoming parallel. This type of substrate inhibition is uncompetitive (Cleland, 1970).

\section{Discussion}

\section{Reaction mechanism}

The initial-velocity patterns obtained with respect to both substrates were of converging plots intersecting to the left of the ordinate (Figs. $1 a$ and $1 b$ ). This result indicated that the reaction mechanism was not Ping Pong but sequential, the initial velocity of reaction being given (Cleland, 1963a, 1970) by:

$$
v=\frac{V_{1}[\mathrm{~A}][\mathrm{B}]}{K_{\mathrm{s}}^{\mathrm{A}} K_{\mathrm{m}}^{\mathrm{B}}+K_{\mathrm{m}}^{\mathrm{B}}[\mathrm{A}]+K_{\mathrm{m}}^{\mathrm{A}}[\mathrm{B}]+[\mathrm{A}][\mathrm{B}]}
$$

Both random and ordered sequential mechanisms conform to this equation, and it is necessary to distinguish between the two before the values and meanings of the kinetic constants can be correctly assigned. To this end, the product-inhibition studies were carried out: one competitive and three noncompetitive inhibition patterns were observed, as predicted for an ordered sequential Bi Bi mechanism (Morrison, 1965). The only competitive inhibition observed was by $S$-adenosylhomocysteine with respect to $S$-adenosylmethionine, indicating that both combine with free enzyme (E, Scheme 1). Thus $S$-adenosylmethionine is the first substrate (A) to add to the enzyme and $S$-adenosylhomocysteine must be the second product ( $Q$ ) to leave it. Therefore histamine is the second substrate (B) and 1-methylhistamine the first product $(\mathrm{P})$. The non-competitive inhibitions by $S$-adenosylhomocysteine with respect to histamine (Fig. $3 a$ ) and by 1-methylhistamine with respect to histamine (Fig. 2a) are as predicted for Scheme 1, since both products combine with an

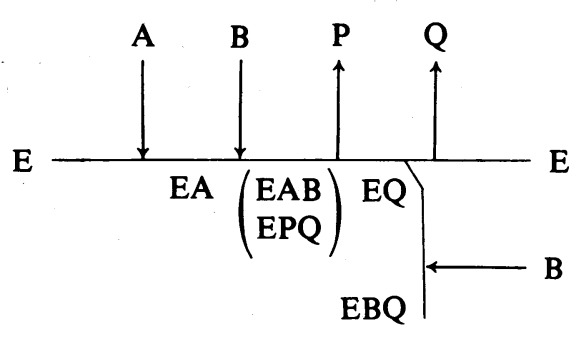

Scheme 1. Reaction mechanism of human skin histamine methyltransferase represented schematically according to the notation of Cleland (1970)

The free enzyme is denoted as $\mathrm{E}, \boldsymbol{S}$-adenosylmethionine as $\mathrm{A}$, histamine as $\mathrm{B}, 1$-methylhistamine as $\mathbf{P}$ and $\boldsymbol{S}$-adenosylhomocysteine as $\mathrm{Q}$. enzyme form that is different from that with which the variable substrate combines (Cleland, 1970). However, the inhibition by 1-methylhistamine with respect to $S$-adenosylmethionine (Fig. $2 b$ ) at first appeared inconsistent with Scheme 1, since it was apparently uncompetitive, with the plots appearing to intersect on the ordinate. Close inspection, as described above, led us to believe that the inhibition pattern was in fact non-competitive, with a large uncompetitive component compared with the competitive component.

The non-competitive inhibition by the first product with respect to the first substrate in an ordered $\mathrm{Bi} \mathrm{Bi}$ mechanism is expected to become uncompetitive at high concentrations of the second substrate, but the concentration of histamine at which uncompetitive inhibition was approached was $10 \mu \mathrm{M}$, hardly a high concentration in view of the estimated $K_{\mathrm{m}}^{\text {histamine }}$ value of about $4 \mu \mathrm{M}$ (Table 1). Yet substrate inhibition by histamine was observed at concentrations immediately above $10 \mu \mathrm{M}$, and this concentration was the maximum that could be used in our kinetic studies and assay of total enzyme activity. Substrate inhibition is not normally expected to occur at physiological concentrations, and it is of interest in that the concentrations at which it occurs set upper limits to likely substrate concentrations in vivo. In such a context, $10 \mu \mathrm{M}$ histamine may be a 'high' substrate concentration in this particular enzyme-catalysed reaction, and this would be consistent with the non-competitive inhibition approaching the uncompetitive pattern.

The uncompetitive substrate inhibition observed with histamine (Fig. 4) is characteristic of an ordered sequential $\mathrm{Bi} \mathrm{Bi}$ mechanism and provides further evidence that this mechanism operates for human skin histamine methyltransferase. It occurs when the second substrate to add to the enzyme can form a dead-end complex with EQ (see Scheme 1).

Since the mechanism of reaction is shown to be ordered $\mathrm{Bi} \mathrm{Bi}$, it is only appropriate to calculate a dissociation constant for the first substrate to add to the enzyme; our estimates of the dissociation constant for $S$-adenosylmethionine, $K_{s}^{\mathrm{A}}$, are presented in Table 1.

Little work has been done on histamine methyltransferase from human tissues, and the apparent $K_{\mathrm{m}}$ values that have been quoted are of little value in characterizing the enzyme prepared from different sources. Zeiger et al. (1976) reported apparent $K_{\mathrm{m}}$ values for histamine methyltransferase from human monocytes. Axelrod \& Vessell (1970) showed two peaks of histamine methyltransferase activity from human liver on starch-block electrophoresis with different apparent $K_{\mathrm{m}}$ values for histamine, indicating the presence of isoenzymes. Although we used an unpurified preparation of histamine methyltransferase from human skin, there was no evidence from 
the initial-velocity data for the presence of isoenzymes.

Kinetic studies to elucidate the reaction mechanism of histamine methyltransferase have been performed on purified preparations from animal sources, but have given conflicting results. Our findings for the reaction mechanism are consistent with those of Barth et al. (1975) for pig gastricmucosa histamine methyltransferase, purified 126fold. They reported that the mechanism was ordered $\mathrm{Bi} \mathrm{Bi}$ on the basis of initial-velocity and productinhibition studies, with $S$-adenosylmethionine being the first substrate to add to the enzyme. The $K_{\mathrm{m}}$ values for histamine and $S$-adenosylmethionine were 17.1 and $8.7 \mu \mathrm{M}$ respectively. Thithapandha \& Cohn (1978) produced initial-velocity values that were consistent with a Ping Pong mechanism for guineapig brain histamine methyltransferase, purified 200fold. Their $K_{\mathrm{m}}$ values for histamine and $S$-adenosylmethionine were 43 and $9.7 \mu \mathrm{M}$ respectively. However, they only studied inhibition by one product, 1-methylhistamine, which they found to inhibit non-competitively with respect to histamine and competitively with respect to $S$-adenosylmethionine. We have shown that human skin histamine methyltransferase was inhibited by 1methylhistamine non-competitively with respect to both substrates (Fig. 2). Thithapandha \& Cohn (1978) predicted that $S$-adenosylhomocysteine should inhibit competitively with respect to histamine and non-competitively with respect to $S$ adenosylmethionine in order to be compatible with the Ping Pong mechanism that they were suggesting. We found for the human skin enzyme that $S$-adenosylhomocysteine inhibited non-competitively with respect to histamine and competitively with respect to $S$-adenosylmethionine (Fig. 3). Similar results to ours were obtained for product inhibition by $S$-adenosylhomocysteine for guinea-pig brain histamine methyltransferase by Baudry et al. (1973), and for the enzyme from pig gastric mucosa by Barth et al. (1974).

Substrate inhibition by histamine at concentrations greater than $10 \mu \mathrm{M}$ has previously been described by Taylor \& Snyder (1972) for histamine methyltransferase from various mouse tissues and by Barth et al. (1973) for pig gastric-mucosa histamine methyltransferase, although none of these authors studied the nature of the inhibition. Thithapandha \& Cohn (1978) showed no substrate inhibition by histamine at concentrations up to $135 \mu \mathrm{M}$, the highest concentration used in their kinetic studies.

\section{Role of histamine methyltransferase in human skin}

Histamine is released from human skin mast cells in response to trauma, toxins and allergic immunological reactions, and becomes available as an inflammatory mediator producing itching, redness and oedema. If the released histamine is freely accessible to a high-capacity inactivating enzyme, a rapid decrease in locally high histamine concentrations would occur, diminishing the severity of the overall inflammatory reaction. The recovered enzyme activity that we measured for the two skin samples was relatively low in comparison with the total potentially available substrate if there were complete mast-cell degranulation with the release of all stored histamine. Thus human skin would not appear to possess sufficient enzyme activity to achieve a rapid decrease in histamine concentration in the 5-10 min that it takes for a histamine reaction to develop. The phenomenon of substrate inhibition by histamine at relatively low concentrations also indicates that the enzyme is not well-adapted to dealing with the high local histamine concentrations that occur after mast-cell degranulation. Furthermore, histamine methyltransferase is an intracellular enzyme, requiring that histamine penetrates the cell membrane before methylation can occur, and it is not yet certain that this penetration is possible. These factors suggest that histamine methyltransferase may not have an important modulating role in acute histamine-mediated inflammatory conditions in human skin. However, since skin is a large organ by weight and highly vascular, the total skin enzyme activity could play an important part in lowering raised blood histamine concentrations, assuming that exogenous histamine can penetrate the intracellular compartment. Methylation of histamine to form 1-methylhistamine has been shown to be the major primary step in the catabolism of administered $\left[{ }^{14} \mathrm{C}\right]$ histamine in man, as demonstrated by the presence of metabolites in the urine (Schayer, 1959). Therefore histamine must be able to penetrate the cells of at least some tissues in order to be methylated.

We thank the Department of Plastic Surgery at Mount Vernon Hospital, Middlesex, for their co-operation in providing the human skin samples. We are grateful to the Medical Research Council for financial support.

\section{References}

Axelrod, J. \& Vessell, E. S. (1970) Mol. Pharmacol. 6, 78-84

Barth, H., Niemeyer, I. \& Lorenz, W. (1973) Agents Actions 3, 138-147

Barth, H., Niemeyer, I. \& Lorenz, W. (1974) Agents Actions 4, 186-188

Barth, H., Lorenz, W. \& Niemeyer, I. (1975) Abstr. Int. Congr. Pharmacol. 6th 96

Baudry, M., Chast, F. \& Schwartz, J. C. (1973) J. Neurochem. 20, 13-21

Brown, D. D., Tomchick, R. \& Axelrod, J. (1959) J. Biol. Chem. 234, 2948-2950 
Cleland, W. W. (1963a) Biochim. Biophys. Acta 67, 104-137

Cleland, W. W. (1963b) Biochim. Biophys. Acta 67, 173-187

Cleland, W. W. (1963c) Biochim. Biophys. Acta 67, 188-196

Cleland, W. W. (1970) Enzymes 3rd Ed. 2, 1-65

Florini, J. R. \& Vestling, C. S. (1957) Biochim. Biophys. Acta 25, 575-578

Francis, D., Greaves, M. W. \& Yamamoto, S. (1977) Br. J. Pharmacol. 60, 583-587

Lowry, O. H., Rosebrough, N. J., Farr, A. L. \& Randall, R. J. (1951) J. Biol. Chem. 193, 265-275

Morrison, J. F. (1965) A ust. J. Sci. 27, 317-327
Schayer, R. W. (1959) Physiol. Rev. 39, 116-126

Shore, P. A., Burkhalter, A. \& Cohn, V. H. (1959) J. Pharmacol. Exp. Ther. 127, 182-186

Snyder, S. H. \& Axelrod, J. (1965) Biochim. Biophys. Acta 111, 416-421

Taylor, K. M. \& Snyder, S. H. (1972) Mol. Pharmacol. 8, 300-310

Thithapandha, A. \& Cohn, V. H. (1978) Biochem. Pharmacol. 27, 263-271

Wilkinson, G. N. (1961) Biochem. J. 80, 324-332

Yamamoto, S., Francis, D. \& Greaves, M. W. (1976) Clin. Exp. Immunol. 26, 583-589

Zeiger, R. S., Yurdin, D. L. \& Colten, H. R. (1976) J. Allergy Clin. Immunol. 58, 172-179 